\title{
Spatial function regionalization and governance of coastal zone: A case study in Ningbo City
}

\author{
SUN Wei ${ }^{1,2},{ }^{*}$ CHEN Cheng ${ }^{1,2}$, WANG Lei ${ }^{1,2}$ \\ 1. Nanjing Institute of Geography and Limnology, CAS, Nanjing 210008, China; \\ 2. Key Laboratory of Watershed Geographic Sciences, CAS, Nanjing 210008, China
}

\begin{abstract}
Reasonable development and utilization of spatial resources in the coastal zone not only affects the development quality of the marine economy but also impacts the utilization efficiency of spatial resources, playing an important role in regional sustainable development. Depending on the natural, economic, and societal characteristics of a region, research topics such as using relevant methods to divide the coastline, proper spatial development of the coast, protecting coastal zones, and achieving higher spatial resource distribution efficiency have recently become hot topics in geographic research. Most of the scholars construct the evaluation index system from the perspective of economic and ecological factors and undertake some exploration of the division methods. However, the selection of indicators for a coastal zone needs a different and more scientific approach. There is a need for emphasizing the overall strategy of land-ocean integration in developing spatial resources in a coastal zone. Taking the coastal zone in Ningbo as an example, this paper develops a new evaluation framework and spatial function regionalization method that is used to divide the coastline and coastal zone. Based on the perspective of overall strategy for the land and ocean, we evaluate the suitability of coastline development. We then propose the spatial function regionalization of the coastal zone. Finally, based on the status quo of spatial development in Ningbo, we divide the coastal zone into ecological space, production space and living space, and propose adjustment directions and control requirements for the different types of spatial layouts.
\end{abstract}

Keywords: coastal zone; coastline; spatial function regionalization; spatial governance; Ningbo City

\section{Introduction}

The ocean environment is an important resource for the survival and development of human society. Currently, we are confronted with three threats, "the gradual dry-up of resources, the increasing environmental deterioration, and the constant population rise" on the surface of land; therefore, the ocean has become one of the decisive factors for determining a country's status and economic strength (Bronfenbrenner, 2004). Exploiting ocean resources and developing marine economy has become a global pursuit (Grantham et al., 2011). Such exploitation of ocean resources even affects national sovereignty and territorial integrity. China

Received: 2017-06-30 Accepted: 2017-12-01

Author: Sun Wei (1980-), Associate Professor, specialized in regional development and plan. E-mail: wsun@niglas.ac.cn

*Corresponding author: Chen Cheng, PhD, E-mail: chchen@niglas.ac.cn 
has also considered the marine economy as one of its important components of economic development. In 2016, national marine GDP was $7.05 \times 10^{3}$ billion RMB yuan, accounting for $9.5 \%$ of the national GDP (SOA, 2017). It is foreseeable that in the upcoming 20-30 years, the marine economy will become extremely important in the competition over Chinese coastal zones. The coastal zone, as a special geographic transition area from ocean to land, is an important component of the marine economy; therefore, rationally developing spatial resources in the coastal zone becomes a key issue (Goble et al., 2014).

Armstrong et al. (1986) first argued that resources in the coastal zones should be managed comprehensively and integratedly. Since then, integrated coastal zone management (ICZM) has gradually replaced the fragmented and closed management methods (Duck, 2012). The approach of ICZM aims to avoid the excessive development and destruction of spatial resources in coastal zones through reasonable planning and project development under the concept of sustainable development (Najafinasab et al., 2015; Ramessur, 2015). It includes detailed aspects such as the occupation of an ecological coastline for economic development, the pollution of water areas, the harmonious development of spatial resources, and the mitigation of disasters and risks (McGlashan and Duck, 2013; Marre et al., 2015). The coastal zone not only carries the function of high population and industry concentration but also demands the maintenance of good ecological environments. Essentially, in addition to the internal labor division of production, a balance between economic development and ecological protection is also required (Dreizis, 2015; Ramsey et al., 2015; Ajith, 2016). Due to the differences in resource endowment, factor structure, natural environment, etc., each area of a coastal zone has a different status and plays a different role in the overall development pattern (Santoso and Halog, 2017). Thus, allocating production elements and spatial resources to all areas and requiring them to undertake the same large-scale and high-strength economic and social activities will ensure that the subjects at all levels participate in the regional competition of industrialization, and thus lead to the occupation and consumption of coastal zone and marine resource environment (Gleason et al., 2010; Domínguez-Tejo et al., 2016).

Obviously, this situation is difficult to sustain in the long run. Therefore, function regionalization of the coastal zone is necessary for realizing sustainable development. The function regionalization has become an important means of planning the division of labor for regional spaces as a whole (Sun, 2010). Along with the balanced spatial development and the presentation of the concept of the "Principal Functional Zone" in China, the exploration and application method for regionalization has become one of the hot topics in geographic research. Principal Functional Zone was initiated to divide territorial space into different zones of optimized development, key development, restricted development and prohibited development according to the carrying capacity, development potential and current development status of the resource environment. The conceptual discussions of the principal functional zone such as a brand-new space division mode (Fan, 2007; Chen, 2008), and the division method and its empirical study have become relatively mature (Sun, 2013; Altunkaynak, 2015). In addition, research on the spatial development suitability regionalization from the perspective of economic development and ecological protection has been developed widely. By considering natural elements such as ecological importance, disaster vulnerability and environmental capacity and socio-economic factors such as economic development level, population and traffic accessibility, we divide the territory into development-type and protection-type spatial function areas (Gu et al., 2007; Sun et al., 2009; Bradley et al., 2016; Huang et al., 2017). 
Actually, to develop and utilize marine resources reasonably, the marine management department of China and academic circles have carried out numerous studies on marine function regionalization. Based on the natural attributes of ocean and by means of index and coordination methods, etc., various scholars have divided different marine spaces into port shipping areas, fishery resources utilization and conservation areas, mineral resources utilization areas, tourism areas, sea water resources utilization areas, marine energy utilization areas, engineering for ocean utilization areas, marine protection areas, special use areas, reserve areas, etc.; they have thus provided a scientific basis for the systematic development and reasonable utilization of marine resources (Liang, 2005). However, marine function regionalization considers only the ocean, but never considers the land areas and their influences, while the division of principal functional zone focuses only on land areas, and as such, the two are separate from each other. However, the use of the spatial resource in the coastal zone, as a special region for the interconnection of ocean and land, is not only limited to land space but also depends on the ocean-land relationship. It is also not only limited to the background supply conditions of natural resources and ecological environment but also would need to consider the production and living demands of local residents. Therefore, based on the existing research on spatial regionalization, this paper focuses on discussing the methods for coastline function division, and uses it to divide the coastline of Ningbo city into three types, namely, ecological coastline (EC), production coastline (PC), and living coastline (LC). The paper also attempts to establish the method for dividing the coastal zone into three kinds of space, namely, ecological space (ES), production space (PS), and living space (LS). This paper provides a scientific basis for the systematic development and regulation of spatial resources in the coastal zone.

\section{Research area and data sources}

Ningbo is a core area of the Zhejiang Marine Economy Development Demonstration Area, and a nationally famous port city (Figure 1). With a total area of $9,365 \mathrm{~km}^{2}$, the city has a coastline of $1562 \mathrm{~km}$ (including $788 \mathrm{~km}$ mainland coastline and $774 \mathrm{~km}$ island coastline). Along with the development of urban production and living in the coastal zone, industrial and domestic sewage production has continued to increase. The increase in total sewage drained to the sea, along with the construction of large chemical and electric power industries close to the port, have led to an increase in the frequency of marine pollution accidents, which further impacts both the marine ecological environment and fisheries' breeding and production. With the development, the extents of natural reserves such as marine ecology, shoals and wetlands have decreased, and the area under natural shoals and wetlands has increasingly reduced. This reduction in natural reserves obviously resulted in deterioration of the marine ecological environment and of the areas that were relied upon for the production of fish, shrimp, crab, seashells, etc., eventually reducing the overall health of marine organisms. In the face of a new round of coastal development, Ningbo should first consider the balance between economic growth and ecological protection.

Based on the established database and according to the existing natural, geographic and development conditions, this paper divides the mainland coastline of Ningbo into different coastal segments. The indexes in this paper are selected from the aspects of natural condition, hydrological power, economic development, etc. By means of dominant factor combination, 


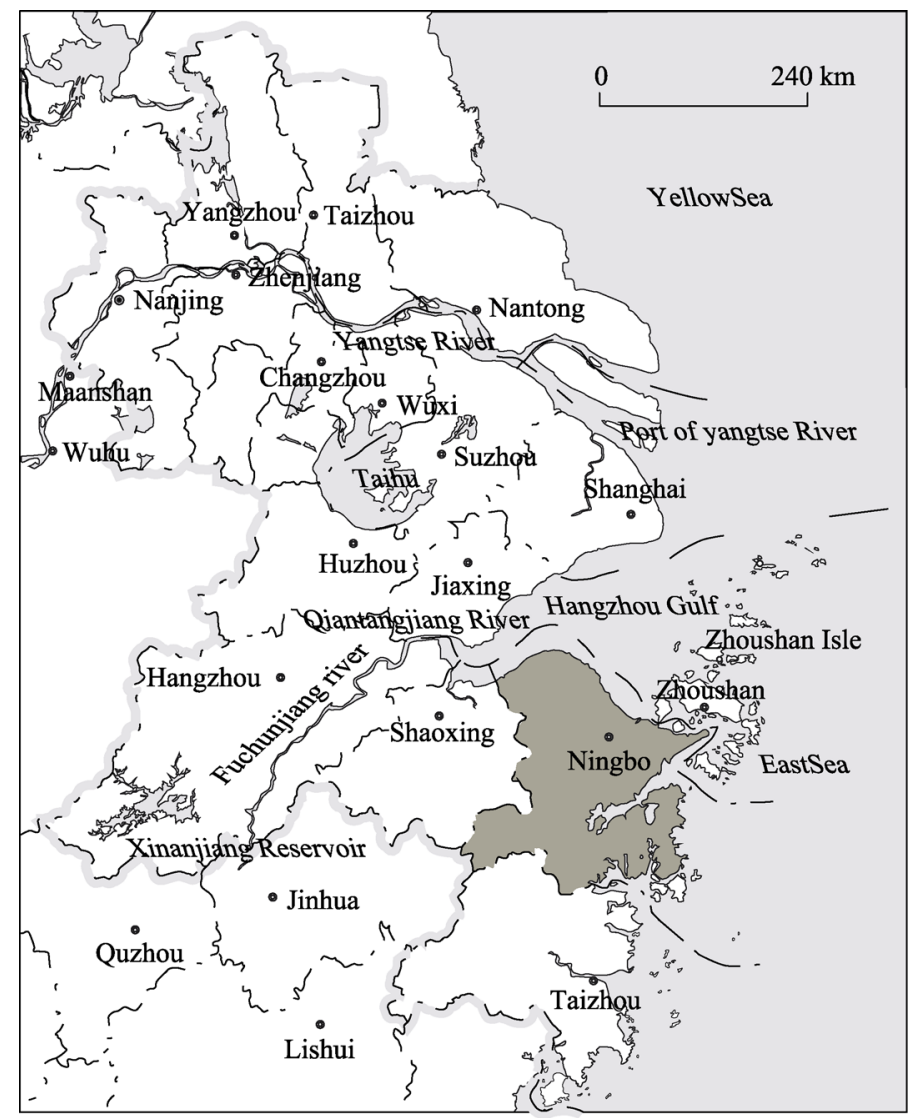

Figure 1 Location of Ningbo city in the Yangtze River Delta

the paper evaluates the suitability of each coastal segment for ecological, production and living functions. The different coastline segments are explained further. The first is the EC which indicates the coastline with great significance for ecological protection, and generally includes the coastline of natural reserves, fishery germplasm resource reserves, important coastal wetlands, etc. The second is the PC, which indicates the coastline of port construction and industrial development. Finally, the LC indicates the coastline of urban and tourism development. By comprehensively overlaying factors such as ecological areas, disaster risks, environmental capacity, water and soil resources, hinterland economic development, and traffic accessibility, the suitability of the coastline for different categories of development or protection can be evaluated, which forms the basis for the proposed divisions of ES, PS and LS of the coastal zone (Figure 2).

This paper, by putting forward the different spatial development and regulations, provides not only a reference for Ningbo to make decisions on a new round of spatial development in the coastal zone and the arrangement of the marine economy but also a scientific basis for related sector plan-making.

Current land use data (in 2015) from Spot5 remote sensing images with $1.5 \mathrm{~m}$ resolution is interpreted. The population data is from the Ningbo Statistical Yearbook 2016. The data of important ecological areas, disasters and water environmental capacity are extracted from relevant maps and special planning information. Traffic data is compiled by digitizing the Comprehensive Traffic Planning Chart 2003-2020. The coastline utilization data is collected 
from sources such as the Master Planning of Ningbo-Zhoushan Port Development, the Marine Function Zoning of Ningbo (2006-2020), and other relevant planning documents.

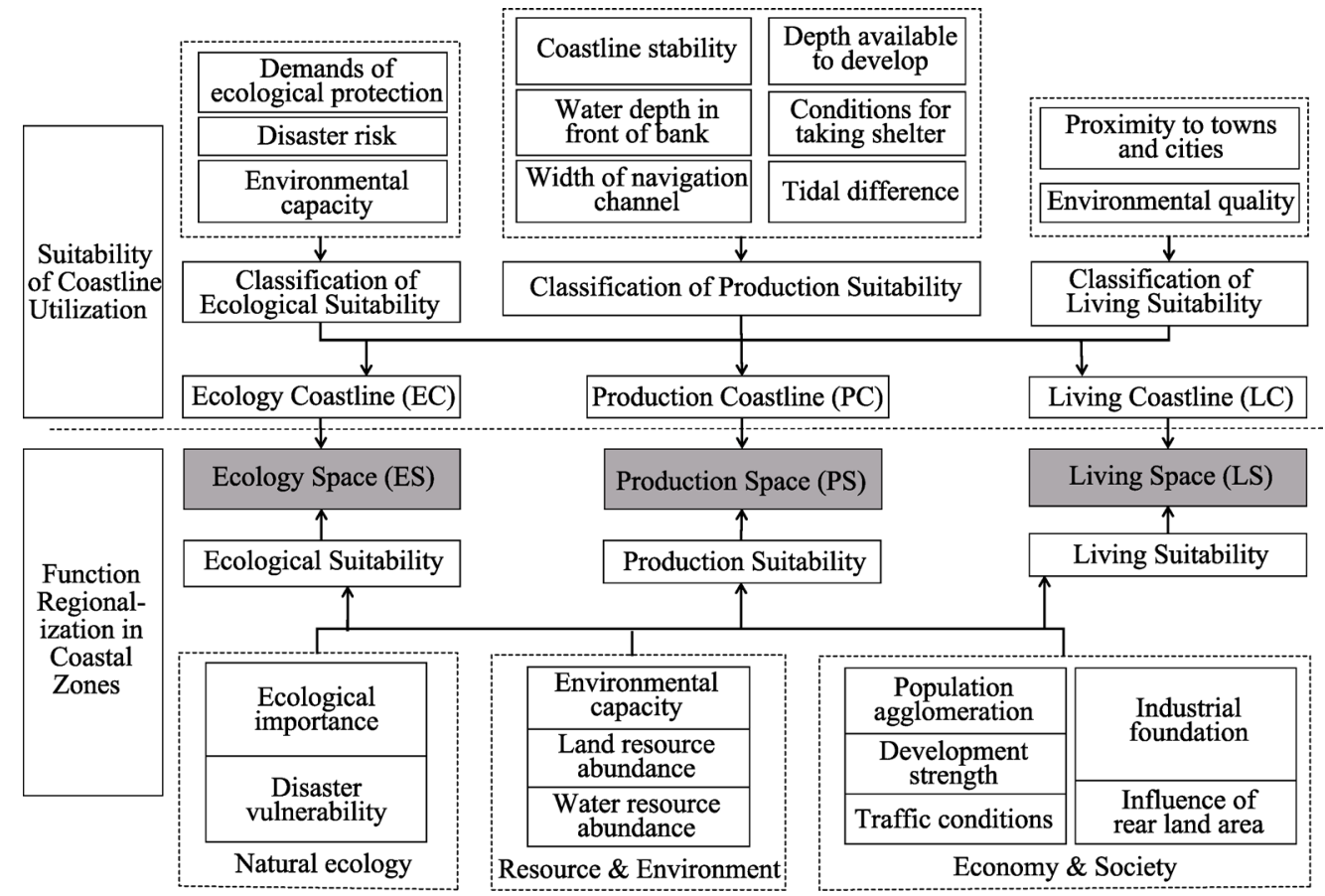

Figure 2 Technical route of spatial function regionalization in coastal zone

\section{Evaluation of the suitability for coastline utilization}

According to the physical geography and actual development conditions, the coastline of Ningbo is divided into 41 coastal segment evaluation units. The determination of evaluation indexes should consider not only the restrictions of ecological protection and environmental capacity but also the supporting functions of natural conditions for developing the marine economy. Furthermore, the relationship between coastline and hinterland, and the harmony among EC, PC and LC should also be given due consideration. The ecological suitability considers factors such as ecological importance, environmental capacity and disaster risk. Ecological importance reflects the importance of maintaining biodiversity, water conservation, and special habitat protection. Disaster risk reflects the possibility of and loss caused by geological disasters. On the other hand, production suitability considers influences on port construction and industrial development, and the relatively stable natural factors such as port navigation conditions. Marine environmental capacity represents the pollutant-carrying capacity of marine water bodies. Port navigation conditions includes coastline stability, water depth in front of seashore, width of navigation-channel water area, depth available to develop in land area, conditions for taking shelter from the wind, and offshore tide, and reflects the natural conditions for the passing through and berthing of ships. Last but not least, living suitability considers indexes such as environmental quality and proximity to towns and cities. Environmental quality represents the comfort of human habitation, while the proximity to towns and cities reflects the availability/accessibility of public services (Figure 3). 


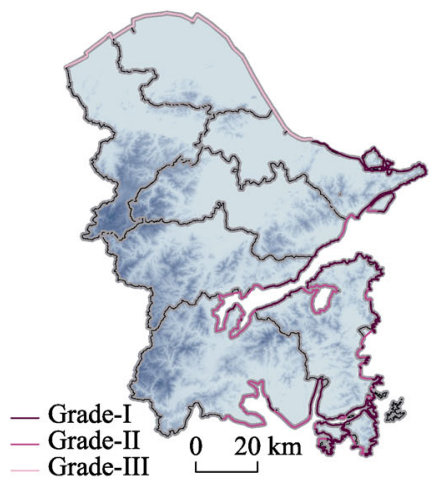

(a) Coastline stability

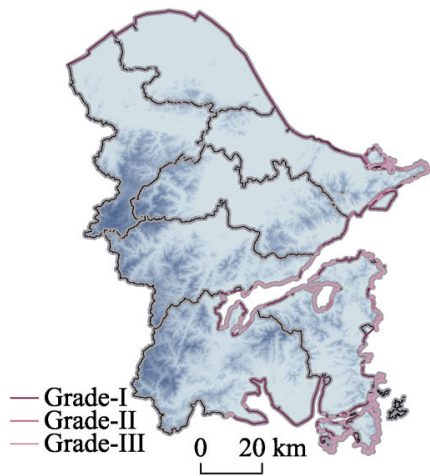

(d) Depth available to develop

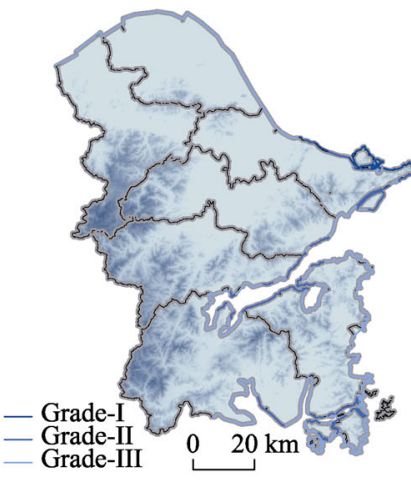

(b) Water depth in front of bank

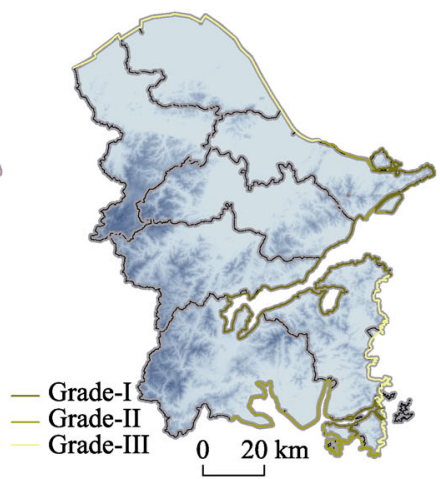

(e) Conditions for taking shelter

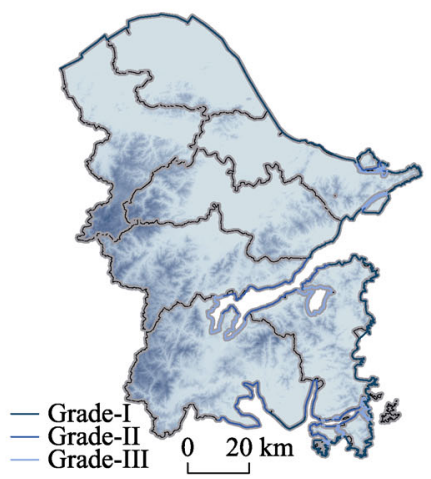

(c) Width of navigation channel

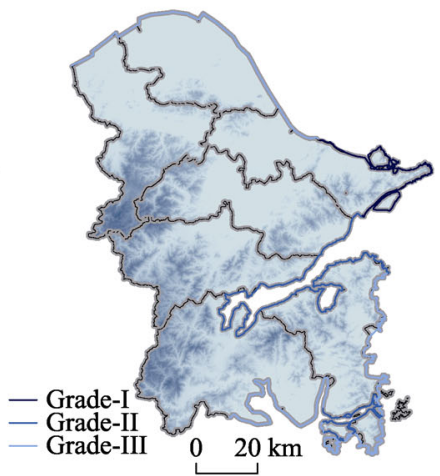

(f) Tidal difference

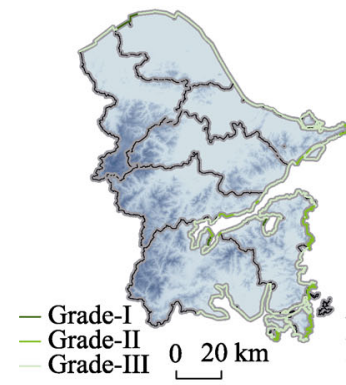

(g) Ecological importance

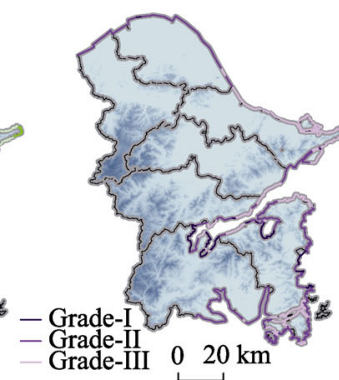

(h) Environmental capacity

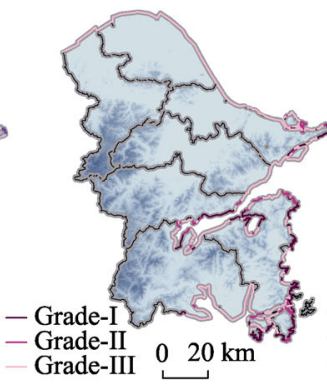

(i) Disaster risk

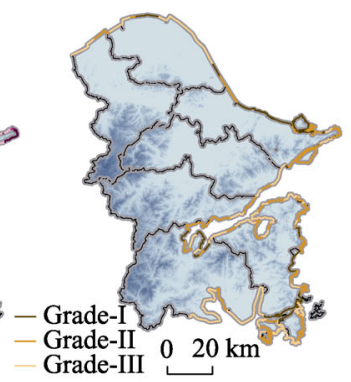

(j) Proximity to towns and cities

Figure 3 Evaluation indicators of coastline suitability

\subsection{Evaluation of the ecological suitability of coastlines}

From the perspective of ecological importance, while wetland ecosystem, important fishery categories, and coastal segments reserve are classified as grade-I, scenic tourist areas and tourism resort coastal segments, and other coastal segments are classified under grade-II and grade-III, respectively.

From the perspective of disaster risk, the steeper the topography is, the greater the impact of disaster risk will be. The coastlines with gradient of less than $5^{\circ}, 5^{\circ}-15^{\circ}$, and more than $20^{\circ}$ are classified under grade-I, grade-II, and grade-III coastlines, respectively.

As shown in the figure of marine environmental capacity, the higher the requirement of 
target water quality is, the higher the requirements on coastline protection will be. Therefore, the coastline of class-I water area is classified as grade-I, that of class-II water areas is classified as grade-II coastline, and that of class-III and class-IV water areas is regarded as grade-III.

According to a comprehensive analysis based on the three above-mentioned indexes, grade-I ecological suitability coastlines are mainly distributed in the southern part of Xiangshan Bay, in the western part of Xihu Port, and to the side of Hangzhou Bay Bridge. These coastlines are close to important ecological reserves and have relatively lower environmental capacities. Grade-II coastlines are distributed alongside Xiangshan Bay and in the southeastern part of Xiangshan County. Inland from these coastlines, the landform presents substantial terrain relief and has a relatively high risk of geological disaster. The other coastlines have relatively poor ecological suitability (Figure 4a).

\subsection{Evaluation of the production suitability of coastlines}

From the perspective of coastline stability, a stable seashore has a stable foundation that is suitable for port development and construction is classified under grade-I of production suitability. On the other hand, while a slow silt-growing coastline is classified under grade-II, a silt-growing coastline has an instable foundation and high development cost and is classified under grade-III.

As shown from the index of the water depth in front of seashore, the coastlines with a -10 $\mathrm{m}$ fathom line and a distance of less than $500 \mathrm{~m}$ from the seashore have good water depth and are classified as grade-I production suitability, those with a $-10 \mathrm{~m}$ fathom line and a distance of $500-1000 \mathrm{~m}$ from the seashore are classified under grade-II and those with a $-10 \mathrm{~m}$ fathom line and a distance of less than $1000 \mathrm{~m}$ from the seashore are classified as grade-III.

Based on the index of the width of navigation channel water areas, the coastal segments with navigation channel water areas of $1000 \mathrm{~m}$ and above in width are convenient for ships to pass through, berth and turn in, and they should be taken as grade-I, while those with navigation channel water areas of $400-800 \mathrm{~m}$ in width should be regarded as grade-II, and those with navigation channel water areas of $400 \mathrm{~m}$ or less in width should be regarded as grade-III.

Considering the index of the depth available to develop in rear land area, the coastal segments with rear land area depth of $1000 \mathrm{~m}$ and above have good supporting conditions for coastline development, and hence should be classified as grade-I, those with rear land area depth of 500-1000 m should be regarded as grade-II and those with rear land area depth of $500 \mathrm{~m}$ and lower should be classified as grade-III.

From the conditions for taking shelter from the wind index perspective, the coastal segments with wave heights of less than $2 \mathrm{~m}$ are relatively stable for ships to pass through and should be classified as grade-I, those with wave heights of $2.0-2.5 \mathrm{~m}$ should be classified as grade-II, and those with wave heights of higher than $2.5 \mathrm{~m}$ should be classified as grade-III.

From the perspective of the index of offshore tide, the coastal segments with tidal range of less than $2.5 \mathrm{~m}$ are relatively stable and should be perceived as grade-I, those with tidal range of 2.5-3.5 m should be classified as grade-II and those with tidal range of more than $3.5 \mathrm{~m}$ should be regarded as grade-III. 
A comprehensive analysis of the abovementioned indexes has shown that the coastlines with grade-I and grade-II production suitability are distributed at the banks of Beilun, Daxie Island, Chuanshan Peninsula, the surrounding areas of Meishan Island, and the gate segments of the Shipu and Xiangshan Ports. The coastal segments of these areas have deep water and relatively good conditions for protection from wind, apart from having spacious rear land area. The grade-III and grade-IV are mainly distributed in the north of the Estuary of Yongjiang River, and the internal areas of Xiangshan Bay, and Sanmen Bay (Figure 4b).

\subsection{Evaluation on the living suitability of coastlines}

According to the quality of habitable environment, the coastal segments having a distance of less than $1000 \mathrm{~m}, 1000-2000 \mathrm{~m}$, and more than $2000 \mathrm{~m}$ from ecological function areas and scenic areas are regarded as grade-I, grade-II, and grade-III living suitability, respectively.

Based on the index of proximity to nearby towns and cities, the coastal segments having a distance of less than $1000 \mathrm{~m}, 1000-2000 \mathrm{~m}$, and more than $2000 \mathrm{~m}$ from adjacent towns and cities should be taken as grade-I, grade-II, and grade-III living suitability, respectively.

A comprehensive consideration of the above-mentioned indexes shows that the coastlines with the grade-I and grade-II living suitability are mainly distributed along the southern part of Xiangshan Bay, in the southeast of Xiangshan County, and in the northwest of Meishan Island. The areas adjacent to these coastlines are close to mountains and rivers and have convenient traffic conditions. The coastlines of other areas have relatively poor living suitability and are mostly regarded as grade-III and grade-IV living suitability (Figure 4c).

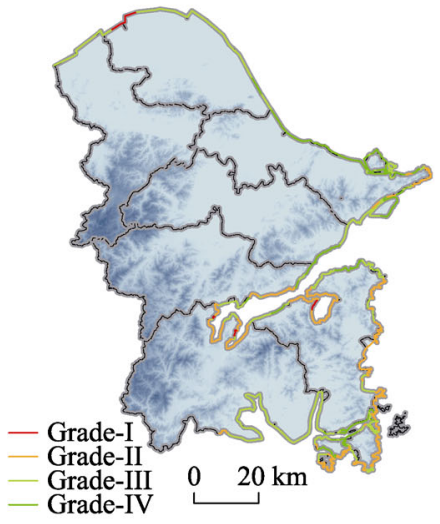

(a) Ecological suitability

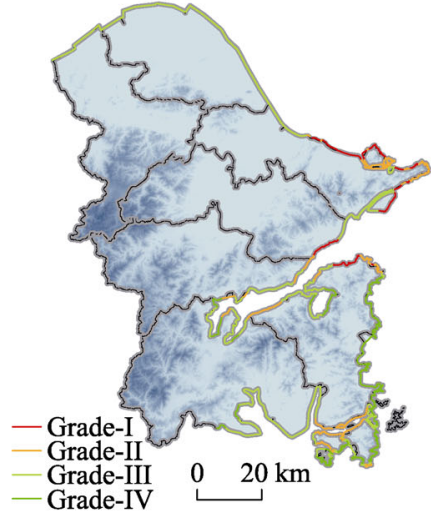

(b) Production suitability

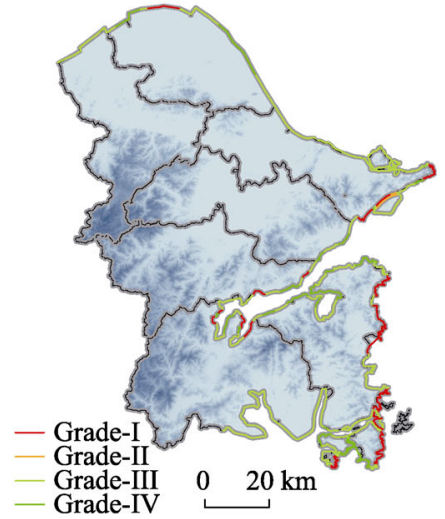

(c) Living suitability

Figure 4 Coastline suitability in Ningbo City

\subsection{Comprehensive evaluation}

Based on the classification of evaluation, this paper compares three grades of each coastal segment and assesses the comprehensive suitability type by combining the current development state. Generally, ECs are distributed in the southern part of Xiangshan Port, in the western part of Xihu Port, in the middle part of the South Bank of Hangzhou Bay, etc., and they maintain the current state and original habitat. PCs are distributed in Zhenhai, Beilun, Daxie, and Meishan islands; the Gate Segment of Xiangshan; and the Shipu Ports. LCs are concentrated in the northwest of Meishan Island, at the bottom of Xiangshan Port, and in the southeast of Xiangshan County (Table 1). 
Table 1 The coastline suitability based on analysis of ecology, production and living suitability

\begin{tabular}{|c|c|c|c|c|c|}
\hline \multirow{2}{*}{ Coastal segment } & \multirow{2}{*}{$\begin{array}{l}\text { Length } \\
(\mathrm{km})\end{array}$} & \multicolumn{3}{|c|}{ Suitability grade } & \multirow{2}{*}{$\begin{array}{l}\text { Function } \\
\text { type }\end{array}$} \\
\hline & & Production & Living & Ecology & \\
\hline Shaoning Boundary - Jiantang River Gate & 23.6 & III & III & III & $\mathrm{EC}$ \\
\hline Jiantang River Gate-500 m upstream of Hangzhou Bay Bridge & 10.0 & III & IV & I & $\mathrm{EC}$ \\
\hline $\begin{array}{l}500 \text { m upstream of Hangzhou Bay Bridge - Fourth Xing- } \\
\text { ci Road }\end{array}$ & 11.0 & III & I & III & $\mathrm{LC}$ \\
\hline Fourth Xingci Road - Hudun Mountain & 60.0 & III & IV & III & $\mathrm{EC}$ \\
\hline Hudun Mountain - North bank of Yongjiang River Estuary & 2.2 & II & III & IV & $\mathrm{PC}$ \\
\hline South bank of Yongjiang River Estuary - Suanshanqi & 6.6 & I & III & IV & $\mathrm{PC}$ \\
\hline Suanshanqi - Puxia & 10.0 & I & III & IV & $\mathrm{PC}$ \\
\hline Puxia $-100 \mathrm{~m}$ to the west of Daxie Bridge & 3.3 & II & III & IV & $\mathrm{PC}$ \\
\hline $\begin{array}{l}100 \mathrm{~m} \text { to the west of Daxie Bridge - East of Yanting Vil- } \\
\text { lage, Baifeng Town }\end{array}$ & 8.1 & II & III & IV & $\mathrm{PC}$ \\
\hline West edge of Waizhi Island - East edge of Waizhi Island & 5.2 & III & III & IV & $\mathrm{EC}$ \\
\hline East edge of Waizhi Island - Jiuwan Village & 3.3 & I & III & IV & $\mathrm{PC}$ \\
\hline Jiuwan Village - Banyuepu & 8.3 & II & III & III & $\mathrm{PC}$ \\
\hline $100 \mathrm{~m}$ to the west of Daxie Bridge - Tuni Mountain & 8.9 & I & III & IV & $\mathrm{PC}$ \\
\hline Tuni Mountain - Fuzhu Village & 5.7 & I & III & IV & $\mathrm{PC}$ \\
\hline Fuzhu Village $-100 \mathrm{~m}$ in the east of Daxie Bridge & 7.9 & II & III & IV & $\mathrm{PC}$ \\
\hline West edge of Lishenma Island - East edge of Lishenma Island & 2.9 & II & III & IV & $\mathrm{PC}$ \\
\hline $\begin{array}{l}\text { West edge of Waishenma Island - East edge of Wai- } \\
\text { shenma Island }\end{array}$ & 3.4 & II & III & III & $\mathrm{PC}$ \\
\hline West edge of Chuanbi Island - East edge of Chuanbi Island & 5.8 & II & III & III & $\mathrm{PC}$ \\
\hline Banyuepu - Xiaoao & 10.1 & II & I & II & $\mathrm{LC}$ \\
\hline Xiaoao - Haikou & 8.1 & II & III & III & $\mathrm{PC}$ \\
\hline Haikou - Guantou Mountain & 4.6 & I & III & IV & $\mathrm{PC}$ \\
\hline Meishan Village - Xiazhitou & 9.0 & I & III & IV & $\mathrm{PC}$ \\
\hline Xiazhitou - Chuangyeqi & 3.7 & III & III & III & $\mathrm{EC}$ \\
\hline Chuangyeqi - Phoenix Mountain & 8.1 & III & I & III & $\mathrm{LC}$ \\
\hline Shizikou - Ganao Village & 8.5 & III & I & III & $\mathrm{LC}$ \\
\hline Xiaogan'ao - Yangsha Mountain & 8.1 & III & I & III & $\mathrm{LC}$ \\
\hline Yangsha Mountain - Linjiang Bridge & 9.3 & III & III & III & $\mathrm{EC}$ \\
\hline $\begin{array}{l}\text { Linjiang Bridge }-500 \mathrm{~m} \text { at the east side of Xiangshan } \\
\text { Bay Bridge }\end{array}$ & 6.6 & I & IV & IV & $\mathrm{PC}$ \\
\hline $\begin{array}{l}500 \mathrm{~m} \text { at the West side of Xiangshan Bay Bridge - Dalie } \\
\text { Mountain }\end{array}$ & 8.6 & II & IV & IV & $\mathrm{PC}$ \\
\hline Dalie Mountain - Shizitou & 2.5 & III & I & III & $\mathrm{LC}$ \\
\hline Shizitou - Huangyantou & 2.8 & II & III & IV & $\mathrm{PC}$ \\
\hline Hengjiang River Gate - Huangni’ao & 5.0 & III & II & III & $\mathrm{EC}$ \\
\hline Huangni’ao - Xianren Shizi Mountain & 5.8 & III & I & III & $\mathrm{LC}$ \\
\hline Xianren Shizi Mountain - Dongchili & 1.9 & II & III & IV & $\mathrm{PC}$ \\
\hline Dongchili - Xifeng Center & 5.0 & III & III & III & $\mathrm{EC}$ \\
\hline Xifeng Center - Shuangshan Mountain & 4.2 & III & III & III & $\mathrm{EC}$ \\
\hline Shuangshan Mountain - Dong'ao & 6.2 & IV & III & II & $\mathrm{EC}$ \\
\hline Dong'ao - Shuangshan Mountain & 1.9 & III & I & II & $\mathrm{LC}$ \\
\hline Shuangshan Mountain - Sanxin Plastic Products Co. & 2.3 & III & IV & I & $\mathrm{EC}$ \\
\hline Sanxin Plastic Products Co., Ltd. - Haitang Road & 2.3 & III & I & II & $\mathrm{LC}$ \\
\hline Haitang Road - Xiachenjia Village & 6.3 & III & III & II & $\mathrm{EC}$ \\
\hline
\end{tabular}




\section{Method for function regionalization in coastal zones}

This evaluation of spatial function regionalization of the coastal zone uses a $1 \mathrm{~km}^{2}$ grid as the evaluation unit, and covers a total of 3379 grid units in the case study coastal zone $(5 \mathrm{~km}$ from coastline to land area). First, the coastline condition is taken as the main factor influencing the spatial development of coastal zone. In principle, the ecology, production and living suitability of coastal zone are in accordance with that of front coastline. On this basis, the indexes such as natural ecology, resource environment, and economics are selected for comprehensive evaluation. As the indicators for the development of different spaces of a coastal zone are different, it is necessary to evaluate the suitability of different indicators for different spaces, such as ecology, production, and living, through index combination methods and their functional directions (Table 2 and Figure 5).

Table 2 Evaluation index system of spatial function regionalization

\begin{tabular}{|c|c|c|}
\hline \multicolumn{2}{|c|}{ Elements } & Index items \\
\hline Natural ecology & Ecological importance & Natural reserve \\
\hline & & Water head site and conservation area \\
\hline & & Forest park \\
\hline & & Mountain land \\
\hline & & Class-I and Class-II marine influencing areas \\
\hline & Disaster vulnerability & Paroxysmal geological hazards \\
\hline & & Slow ground settlement \\
\hline \multirow{5}{*}{$\begin{array}{l}\text { Resource \& } \\
\text { environment }\end{array}$} & Environmental capacity & Surface water environmental capacity \\
\hline & & Atmospheric environmental capacity \\
\hline & Land resource abundance & Quantity: Proportion of land resources available \\
\hline & & Quality: Soil suitable for agriculture (paddy soil distribution) \\
\hline & Water resource abundance & Mean annual precipitation in $1956-2000$ \\
\hline \multirow[t]{5}{*}{ Economy \& society } & Population agglomeration & Population density \\
\hline & Development strength & Proportion of construction land among the area of grid units \\
\hline & Traffic conditions & $\begin{array}{l}\text { Time distance to Ningbo city center, main ports, and } \\
\text { main traffic nodes }\end{array}$ \\
\hline & Industrial foundation & $\begin{array}{l}\text { Distribution of national and provincial developmen } \\
\text { zones and key parks }\end{array}$ \\
\hline & Influence of rear land area & $\begin{array}{l}\text { Population density, urbanization level, completed area } \\
\text { scale, and per capita GDP of the county territory }\end{array}$ \\
\hline
\end{tabular}

Second, weights embody each index's importance and influence on the goal of evaluation. The determination of weight should sufficiently embody the differential characteristics and inherent differences of regional resource conditions and economic development. Here, recoverability and substitutability should be mainly considered for the natural ecological element, while guidance quality should be considered for the socio-economic elements. The indexes having relatively great influences on the socio-economic development and ecological protection should be endowed with a relatively higher weight, while those indexes which are not as stable, or could be changed through engineering technical conditions should be endowed with a relatively lower weight. Weights are determined by a combination of subjective and objective analyses, where subjective weights are analyzed with an analytical hierarchy process, and objective weights are mainly obtained by an entropy evaluation method. 


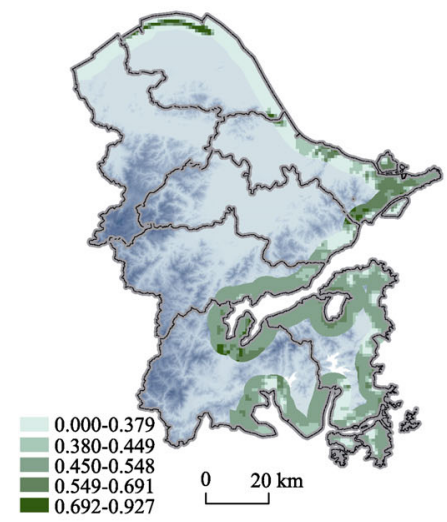

(a) Ecological importance

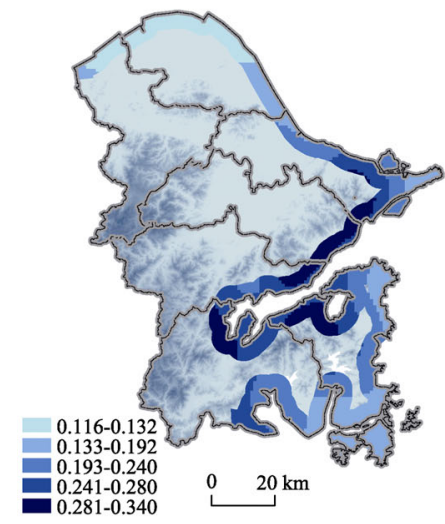

(d) Water resource abundance

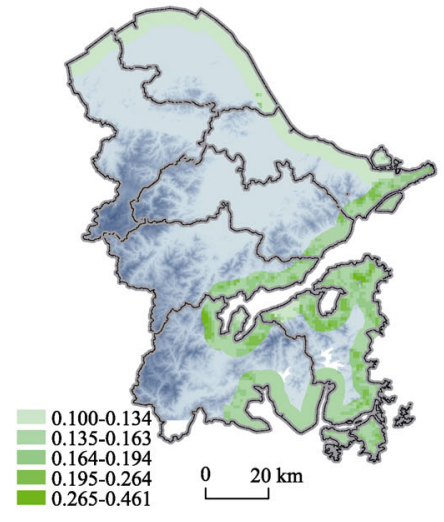

(b) Disaster vulnerability

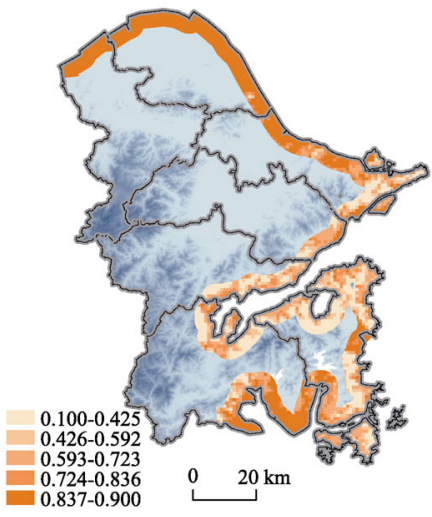

(e) Land resource abundance

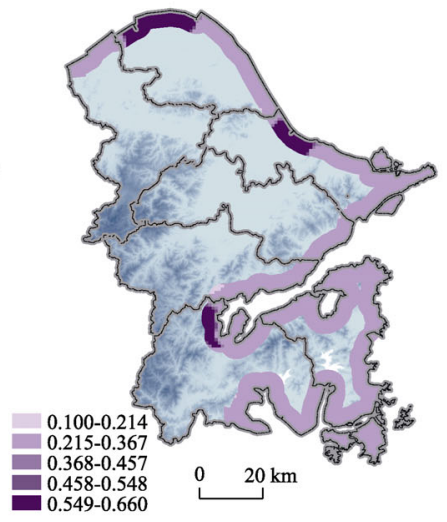

(c) Environmental capacity

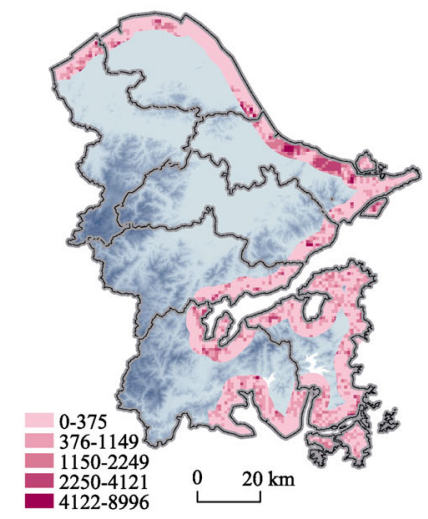

(f) Population agglomeration

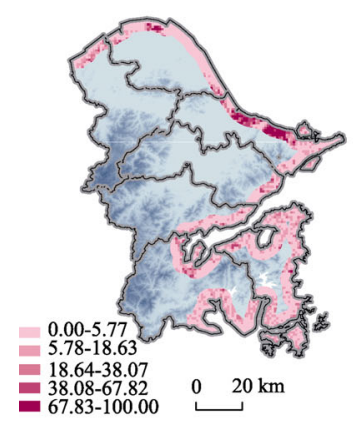

(g) Development intensity

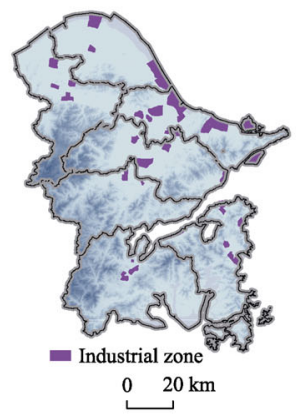

(h) Industrial zone layout

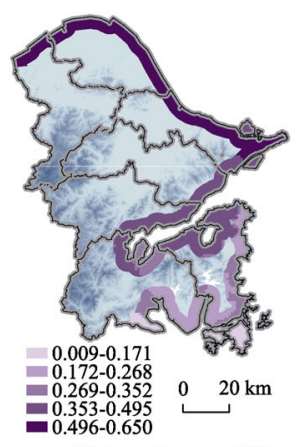

(i) Traffic condition

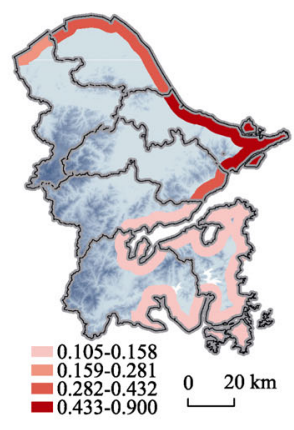

(j) Rear land area condition

Figure 5 Evaluation indicators of spatial function regionalization in the coastal zone

The suitability evaluation of ES should not only highlight the importance of natural ecology and resource environment indexes but also consider the influence of existing development pattern. Natural ecology and resource environment indexes exert guiding functions, while the current development index exerts a restrictive function. The evaluation of the suitability of PS should consider comprehensively the bearing capacity of resource and environment, to the restriction of natural ecology, and to the development foundation of existing economic society. Resource environment and economic society indexes exert guiding 
functions, while natural ecology indexes exert restrictive functions. However, due to mutual occupation of small-scale PS and LS, the population agglomeration index of socio-economy is a restrictive index. The regionalization of LS suitability mainly reflects the advantages and disadvantages of human habitat conditions, whereas the natural ecology index is mainly taken as a restrictive index. However, as it reflects whether the areas surrounding important ecological function areas, mountain lands, etc. have good ecological environment and are suitable for human habitat, the natural ecology index may also be taken as a guiding index. While resource environment and socio-economic indexes mainly exert guiding functions on population layout, but in small-scale evaluation, industrial foundation is a restrictive index for population distribution (Table 3).

Table 3 The selection of indicators and weight about different spatial evaluations

\begin{tabular}{|c|c|c|c|c|}
\hline \multicolumn{2}{|c|}{ Influential elements } & Ecological suitability & Production suitability & Living suitability \\
\hline \multirow{3}{*}{$\begin{array}{l}\text { Coastline } \\
\text { suitability }\end{array}$} & $\mathrm{EC}$ & Guiding (0.30) & Restrictive (0.10) & Restrictive $(0.10)$ \\
\hline & $\mathrm{PC}$ & Restrictive (0.10) & Guiding (0.30) & Restrictive (0.10) \\
\hline & $\mathrm{LC}$ & Restrictive (0.10) & Restrictive (0.10) & Guiding (0.30) \\
\hline \multirow[t]{2}{*}{ Natural ecology } & Ecological importance & Guiding (0.13) & Restrictive (0.09) & Restrictive (0.09) \\
\hline & Disaster vulnerability & Guiding (0.09) & Restrictive (0.03) & Restrictive (0.03) \\
\hline \multirow{3}{*}{$\begin{array}{l}\text { Resource \& } \\
\text { environment }\end{array}$} & Environmental capacity & Guiding (0.08) & Guiding (0.09) & Guiding (0.03) \\
\hline & $\begin{array}{c}\text { Water resource } \\
\text { abundance }\end{array}$ & - & Guiding (0.06) & Guiding (0.09) \\
\hline & Land resource abundance & - & Guiding (0.06) & Guiding (0.06) \\
\hline \multirow[t]{5}{*}{ Economy \& society } & Population agglomeration & Restrictive (0.08) & Restrictive (0.03) & Guiding (0.03) \\
\hline & Traffic condition & - & Guiding (0.03) & Guiding (0.03) \\
\hline & Development intensity & Restrictive (0.07) & - & - \\
\hline & Industrial foundation & Restrictive (0.05) & Guiding (0.06) & Restrictive (0.12) \\
\hline & Hinterland influence & - & Guiding (0.06) & Guiding (0.03) \\
\hline
\end{tabular}

After stepwise hierarchically merging the above-mentioned indexes, parallel and independent indexes are standardized (according to formula 1). Then, the index value is converted into dimensionless numerical value between $[0,1]$. Finally, through a weighted sum (based on formula 2), we may obtain the ecology, production and living suitability indexes of each evaluation unit.

$$
\begin{aligned}
& X=\frac{x^{\prime}-x_{\min }^{\prime}}{x_{\max }^{\prime}-x_{\min }^{\prime}} \\
& A_{i}=\sum_{j=1}^{n} X_{i j} \times W_{j}
\end{aligned}
$$

where $X$ indicates the normalized value, $x^{\prime}$ indicates the value of the element, $x_{\max }^{\prime}$ indicates the maximum value of the element, and $x_{\min }^{\prime}$ indicates the minimum value of the element; $A_{i}$ indicates the ecology, production or living suitability index of unit $i$; $X_{i j}$ indicates the value of element $j$ of unit $i$; and $W_{j}$ indicates the weight of the value of element $j$.

The evaluation results show that the areas with relatively good ecological suitability are concentrated at the west end of Xiangshan Port, Damuyang, and Sanmen Bay. These areas 
basically belong to low-mountain and hilly areas and have relatively small environmental capacity. Beilun, Zhenhai, Meishan, etc., with relatively high development level at present, have relatively low suitability for layout of ecological spaces. The areas with relatively good production suitability are concentrated at Beilun and Zhenhai. In addition, Hangzhou Bay New Town and Shipu Port have relatively high production suitability. These areas are highly developed and are major locations of industrial zones. The local places at Xiangshan Port, Damuyang, and the west of Sanmen Bay have relatively low production suitability. The areas with relatively good living suitability are concentrated at Chuanshan Peninsula, Xiangshan Port, and partial areas at the south bank of Hangzhou Bay. These areas are highly developed at present, closer to mountain areas and have good habitable environment. Zhenhai Chemical Zone, Cidong Shoal Area, Daxie Island, Meishan Island, etc. are industrial development zones or important ecological function areas and are not suitable for large-scale population agglomeration (Figure 6).

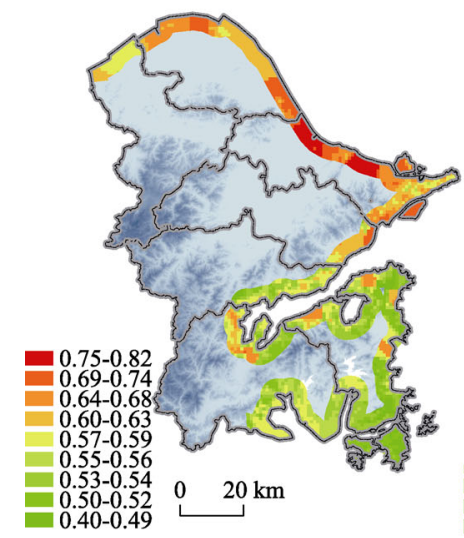

(a) Production suitability

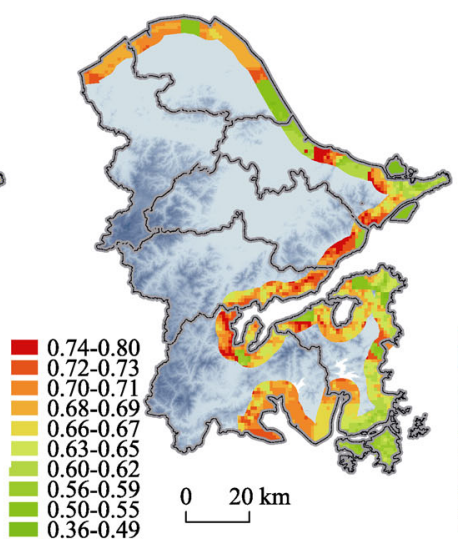

(b) Living suitability

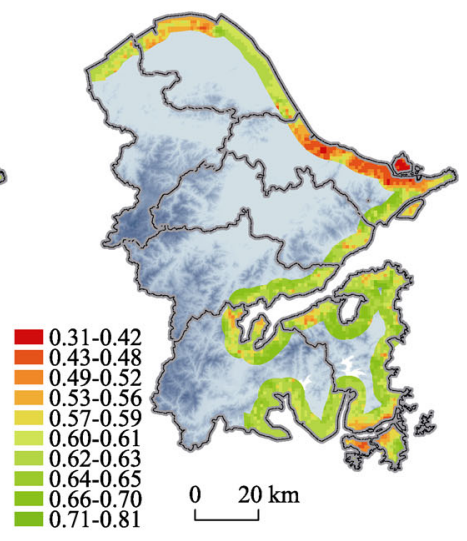

(c) Ecological suitability

Figure 6 Evaluation result of spatial function regionalization in the coastal zone

\section{Conclusion and discussion}

Through a suitability evaluation of coastline utilization and function regionalization of the coastal zone, the coastal territory may be divided into ES, PS and LS. Different control and regulation approaches may be implemented for the different types of zones. The requirements on the control of 41 coastal segments in Ningbo city may be further defined, such as the key development area, the development intensity, and environmental protection. In general, the areas suitable for production spaces in the coastal zone of Ningbo are mainly located at the south bank of Hangzhou Bay, in Cidong, and Beilun-Zhenhai. The living spaces are mainly distributed in the New Town at the south bank of Hangzhou Bay, the Beilun Urban Area, and the partial urban areas inside the Xiangshan Port, Shipu, and the New Town in the East of Xiangshan. Ecological spaces are mainly the natural reserves, forest areas, hilly areas and mountain lands, water conservation areas, important shoals, etc. It is worth mentioning that higher development intensity shall be strictly controlled for areas inside Xiangshan Port and the areas close to the marine space of Sanmen Bay in Ninghai and Xiangshan. These areas, as ecological protection areas and reserves, should not be developed before the conditions become mature. 
Generally, the suitability of coastline utilization and the function regionalization of coastal zone methods basically meet the natural conditions of the spatial development of coastal zone in Ningbo. This provides a scientific basis for promoting sustainable development of the marine economy and the reasonable utilization of coastline and spatial resources in the coastal zone. The outcomes of this paper are not only beneficial for coordinating spatial development and ecological environmental protection in coastal zones, but they also have certain guiding significance for Ningbo's reasonable and orderly layout of the marine economy in the future. In particular, the differential guidance of spatial development could encourage large-scale and high-intensity development in the areas that have relatively few ecological restrictions and vigorous development demand and thereby lower the development intensity of the areas with more sensitive ecological environments and allow them to mainly undertake the function of regional ecological maintenance. On one hand, it could enhance the level of land resource savings and intensive utilization, and lessen the restriction of land resources. On the other hand, it could reasonably protect the ecological environment of marine spaces, mountain lands and hilly areas, maintain the stable structure and function of regional ecological systems, and achieve sustainable development.

From the perspective of regionalization methods, the key to the validity of regionalization results rests with index selection and data reliability. In this paper, for the suitability evaluation of coastline utilization, some port navigation data, hydrological data, and underwater topography data were obtained from secondary sources by interpreting related data and sorting out related research reports. This paper did not use first-hand data, and this limitation should be further complemented and improved in future studies. On the other hand, the utilization of space in the coastal zone is affected by the selection of development mode for the hinterland and by factors at a wider spatial scale. Herein, the study area was considered as a closed space. Thus, this concept will be applied at a wider scale for function regionalization. Additionally, how to integrate the evaluation of ES, PS and LS and show the result on one map, and how to determine the reasonable proportion of coastline utilization and the spatial structure in different coastal zones, all of these need deep research in the future.

\section{References}

Ajith J K, 2016. Concepts and policies of Integrated Coastal Zone Management (ICZM). In: Training Programme on Geomatics for Coastal Zone Management, April 18-22.

Altunkaynak A, 2015. Prediction of significant wave height using spatial function. Ocean Engineering, 106: $220-226$.

Armstrong J M, Ryner P C, 1986. American Ocean Management. Beijing: China Ocean Press.

Bradley J R, Wikle C K, Holan S H, 2016. Regionalization of multiscale spatial processes by using a criterion for spatial aggregation error. Journal of the Royal Statistical Society, 79(3): 815-832.

Bronfenbrenner U E, 2004. Making Human Beings Human: Bioecological Perspectives on Human Development. The SAGE Program on Applied Developmental Science. Sage Publications, 336.

Chen W, 2008. Economic Analysis on Space Equilibrium. Beijing: The Commercial Press. (in Chinese)

Domínguez-Tejo E, Metternicht G, Johnston E et al., 2016. Marine spatial planning advancing the ecosystem-based approach to coastal zone management: A review. Marine Policy, 72: 115-130.

Dreizis Y I, 2015. Integrated coastal zone management is the main mechanism for sustainable development of the sea region. Modeling of Artificial Intelligence, 5(1): 4-8.

Duck R W, 2012. Marine spatial planning: Managing a dynamic environment. Journal of Environmental Policy 
and Planning, 14(1): 67-79.

Fan J, 2007. Scientific foundation of principal function regionalization in China. Acta Geographica Sinica, 62(4): 339-350. (in Chinese)

Gleason M, Mccreary S, Miller-Henson M et al., 2010. Science-based and stakeholder-driven marine protected area network planning: A successful case study from North Central California. Ocean and Coastal Management, 53(2): 52-68.

Goble B J, Lewis M, Hill T R et al., 2014. Coastal management in South Africa: Historical perspectives and setting the stage of a new era. Ocean and Coastal Management, 91: 32-40.

Grantham H S, Mcleod E, Brooks A et al., 2011. Ecosystem-based adaptation in marine ecosystems of tropical Oceania in response to climate change. Pacific Conservation Biology, 17(3): 241-258.

Gu C L, Zhang X M, Liu J Y et al., 2007. The development space regionalization of Yancheng and the deliberation on it. Acta Geographica Sinica, 62(8): 787-798. (in Chinese)

Huang J C, Lin H X, Qi X X, 2017. Spatial development regionalization of the Beijing-Tianjin-Hebei Region from the perspective of spatial governance. Progress in Geography, 36(1): 46-57. (in Chinese)

Liang X B, 2005. Research on the method for marine function regionalization and its application [D]. Tianjin: Tianjin Normal University. (in Chinese)

Marre J B, Thebaud O, Pascoe S et al., 2015. The use of ecosystem services valuation in Australian coastal zone management. Marine Policy, 56: 117-124.

McGlashan D J, Duck R W, 2013. The PDMU approach to the integration of coastal management. Journal of Coastal Research, 26(3): 465-469.

Najafinasab F, Karbassi A R, Ghoddousi J, 2015. Fuzzy analytic network process approach to evaluate land and sea criteria for land use planning in coastal areas. Ocean and Coastal Management, 116: 368-381.

Ramessur R T, 2015. Integrated coastal zone management: Ecological, socio-economic and governance challenges. Journal of Coastal Zone Management, 18: 2. doi: 10.4172/2473-3350.1000e112

Ramsey V, Cooper J A G, Yates K L, 2015. Integrated coastal zone management and its potential application to Antigua and Barbuda. Ocean and Coastal Management, 118: 259-274.

Santoso P B, Halog A, 2017. Science based modelling for supporting integrated coastal zone management. In: Environmental Modeling with Stakeholders. Springer International Publishing, 307-325.

State Oceanic Administration (SOA), 2017. Bulletin of China Marine Economic Statistics. http://www.coi.gov. cn/gongbao/jingji/201703/t20170330_35419.html. 2017-03-30.

Sun W, 2010. Research on the admittance and collocation of elements for spatial function regionalization and governance in urban areas: A case study of Wuxi [D]. Beijing: Graduate University of the Chinese Academy of Sciences. (in Chinese)

Sun W, 2013. The Theory, Methods and Applications of Spatial Function Regionalization. Beijing: Science Press. (in Chinese)

Sun W, Chen W, 2009. Research on urban space development suitability regionalization and layout guide: A case study in Ningbo City. Journal of Natural Resources, 24(3): 402-413. (in Chinese) 